\title{
Article \\ Ceftriaxone Degradation in the Presence of Sodium Halides Investigated by Electrochemical Methods Assisted by UV-Vis Spectrophotometry
}

\author{
Bogdan Tutunaru*(D), Adriana Samide, Simona Iordache, Cristian Tigae, Andreea Simionescu \\ and Alexandru Popescu
}

check for updates

Citation: Tutunaru, B.; Samide, A.; Iordache, S.; Tigae, C.; Simionescu, A.; Popescu, A. Ceftriaxone Degradation in the Presence of Sodium Halides Investigated by Electrochemical Methods Assisted by UV-Vis Spectrophotometry. Appl. Sci. 2021, 11, 1376. https://doi.org/ 10.3390/app11041376

Received: 3 January 2021

Accepted: 30 January 2021

Published: 3 February 202

Publisher's Note: MDPI stays neutra with regard to jurisdictional claims in published maps and institutional affiliations.

Copyright: (c) 2021 by the authors. Licensee MDPI, Basel, Switzerland. This article is an open access article distributed under the terms and conditions of the Creative Commons Attribution (CC BY) license (https:// creativecommons.org/licenses/by/ $4.0 /)$.
Department of Chemistry, Faculty of Sciences, University of Craiova, CUI: 4553380, Calea București 107i, 200478 Craiova, Romania; samide_adriana@yahoo.com (A.S.); sim_iordache@yahoo.com (S.I.); ctigae@yahoo.com (C.T.); andreea.simionescu@edu.ucv.ro (A.S.); popescu_andreea_alexandra@yahoo.com (A.P.) * Correspondence: tutunaruchim@yahoo.com; Tel./Fax: +40-251-597048
Abstract: The electrochemical stability of ceftriaxone (CFTX), belonging to the third generation of cephalosporin antibiotics, was studied by electrochemical measurements recorded on a platinum electrode $(\mathrm{Pt})$ in aqueous solutions containing sodium halides. The electrochemical behavior of ceftriaxone was investigated by cyclic voltammetry $(\mathrm{CV})$ and constant current density electrolysis assisted by UVVis spectrophotometry. Cyclic voltammetry highlighted that the addition of CFTX in sodium halide solutions leads to significant changes in the hysteresis characteristics due to specific interactions with active species from electrolytes, as well as with the platinum electrode surface. After CV, when an exterior electric stimulus in short time (40 s) was applied, the UV-Vis spectra illustrated that CFTX is stable in the presence of $\mathrm{F}^{-}$ions, it is electro(degraded/transformed) in the presence of $\mathrm{Cl}^{-}$and $\mathrm{Br}^{-}$ ions and interacts instantly with $\mathrm{I}^{-}$species. Electrolysis at constant current density confirms the results obtained from cyclic voltammetry, showing that (i) in the presence of fluoride ions CFTX gradually decomposes, but not completely, in about $60 \mathrm{~min}$, without identifying a reaction product; (ii) chloride and bromide ions determine the almost complete CFTX electro(degradation/transformation) in 10 and $5 \mathrm{~min}$, respectively, with completion of the electro-transformation reaction after 60 and $30 \mathrm{~min}$, respectively; (iii) instantaneous interactions between CFTX and the iodide ions occurred.

Keywords: ceftriaxone; electrochemical degradation; sodium halides; UV-Vis spectrophotometry; electrodegradation mechanism

\section{Introduction}

The antibiotics detected in hospital, municipal and industrial pharmaceutical wastewaters can lead to selective proliferation of some microorganisms [1,2], and thus their removal from different contaminated resources has become a concern, in recent years, for many researchers [1,2]. Qualitative and quantitative analyses of cephalosporin antibiotics sometimes involve certain impediments due to their complex physical and chemical features. For the analysis of bulk drugs and pharmaceutical compounds contained by biological fluids or wastewaters, spectroscopic, chromatographic and electrochemical methods were reported to be effective [3-7].

Antibiotics are partially metabolized in non-toxic compounds, but often drugs are eliminated as such, having a negative impact on the environment and causing its pollution. The biological release of drugs and their degradation compounds could lead to contamination of surface waters and sediments [8].

Based on antimicrobial properties, the cephalosporins can be classified into the first, second, third and fourth generation. According to this classification, ceftriaxone is the third-generation agent produced by the Fungus Cephalosporinum acremonium, a class of $\beta$-lactam type, used to inhibit the bacterial wall cell synthesis. 
Indirect determination of ceftriaxone using n-propyl alcohol—ammonium sulfate, by extraction or by riboflavin sensitization, represents new ways for its spectrophotometric determination or photooxidation $[9,10]$. Sonoelectrochemical catalytic degradation onto a nanocoated electrode led to a drug removal efficiency of $94 \%$, at a current density of $8 \mathrm{~mA} \cdot \mathrm{cm}^{-2}$ and an ultrasound frequency of $45 \mathrm{kHz}$ [11]. Optimizing of experimental parameters of photo-induced and sonocatalytic degradation revealed a ceftriaxone removal efficiency ranging between $70 \%$ and $95 \%$ [12-16]. These methods were also used for ceftriaxone degradation in the presence of carbon nitride $\left(\mathrm{g}-\mathrm{C}_{3} \mathrm{~N}_{4}\right)$ and different composite materials such as Ag-CsPbBr $3, \mathrm{ZnSe}, \mathrm{BiWO}_{6}$ [17-21].

Indirect electrochemical oxidation was applied for decomposition of biologically active compounds such as vitamins, antibiotics, food additives and pesticides, reaching a good removal performance of these contaminants from wastewaters [22-28].

A new possibility to enhance the degradation degree of ceftriaxone implies the controlled synthesis of nanostructured photocatalysts as $\mathrm{BiWO}_{6}$ nanoflowers, $\mathrm{SnO}_{2}-\mathrm{TiO}_{2} /$ nanographite, $\mathrm{TiO}_{2} /$ nano-graphite, $\mathrm{RuO}_{2}-\mathrm{TiO}_{2} /$ nano-graphite [29-32].

A very important aspect of the pharmaceutical chemistry field consists of the investigation of drug interactions in multicomponent systems that can facilitate decomposition/degradation or transformation into other compounds with adverse and unfriendly effects on the human body. Unwanted drug interactions can also lead to a decrease in the expected effect for which the drug was administered. Medicines/food supplements containing bromine, chlorine, iodine or fluorine can induce partial inactivation of other concomitantly administered drugs due to their interactions with halogen ions which catalyzes the degradation/transformation of the respective pharmaceutical compounds.

In the aforementioned context, in this work, the electro(degradation/transformation) of ceftriaxone (CFTX) was investigated, following two objectives: (i) removal of drug traces from medical wastewater; (ii) the effect of anions of fluoride, chloride, bromide and iodide on the CFTX stability, in aqueous solutions, at a $\mathrm{pH}$ close to neutral and at room temperature. Normal administration and storage conditions were chosen to avoid the introduction into the reaction media of other substances that could cause additional interactions. The CFTX electrochemical degradation/transformation on a platinum electrode was investigated by cyclic voltammetry and constant current electrolysis assisted by UV-Vis spectrophotometry. Based on the experimental results obtained in the presence of different halide ions, the ceftriaxone degradation mechanism was proposed.

\section{Materials and Methods}

\subsection{Materials}

The ceftriaxone (CFTX) (Medochemie Ltd., Limassol, Cyprus) presented the purity for pharmaceutical chemicals (Table 1). All simulated polluted solutions were prepared with distilled water. Some physical properties, CFTX structure and IUPAC name are illustrated in Table 1. The sodium halides as, $\mathrm{NaF}, \mathrm{NaCl}, \mathrm{NaBr}$ and $\mathrm{NaI}$ as well as $\mathrm{Na}_{2} \mathrm{SO}_{4}$ with analytical degree and purity $\geq 99 \%$ were purchased from Merk or Sigma Aldrich.

Table 1. Physical properties of ceftriaxone (CFTX).

disodium(6R,7R)-7-[[(2Z)-2-(2-amino-1,3-thiazol-4-yl)-2-methoxyiminoacetyl]

amino]-3-[(2-methyl-6-oxido-5-oxo-1,2,4-triazin-3-yl)sulfanylmethyl]-8-oxo-5-thia-1azabicyclo[4.2.0]oct-2-ene-2-carboxylate

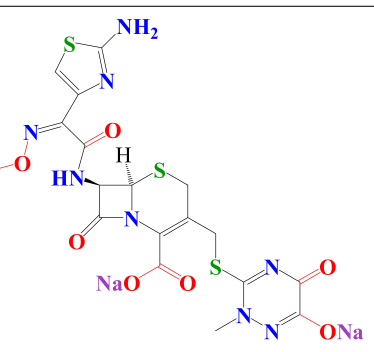

$\mathrm{C}_{18} \mathrm{H}_{16} \mathrm{~N}_{8} \mathrm{Na}_{2} \mathrm{O}_{7} \mathrm{~S}_{3}$

Molecular weight: $598.6 \mathrm{~g} \cdot \mathrm{mol}^{-1}$

Melting point: $155^{\circ} \mathrm{C}$

Solubility: $0.105 \mathrm{~g} \cdot \mathrm{L}^{-1}$

Biological half-life: $5.8-8.7 \mathrm{~h}$ 
The electrochemical experiments were carried out in $100 \mathrm{~cm}^{3}$ of electrolyte solutions containing $0.025 \mathrm{~g} \cdot \mathrm{L}^{-1} \mathrm{CFTX}$ and $0.1 \mathrm{~mol} \cdot \mathrm{L}^{-1} \mathrm{NaX}$ (where $\mathrm{X}$ was one by one: $\mathrm{F}^{-}, \mathrm{Cl}^{-}, \mathrm{Br}^{-}$, $\mathrm{I}^{-}$) vs. a supporting electrolyte containing successively only $0.1 \mathrm{~mol} \cdot \mathrm{L}^{-1} \mathrm{NaX}$.

\subsection{Electrochemical Measurements}

A VoltaLab potentiostat/galvanostat with VoltaMaster 4 software (version 7.8.26338.3, Radiometer Analytical SAS, Lyon, France) was used to investigate the electrochemical behavior of CFTX in simulated wastewaters mentioned above. All the electrochemical experiments were conducted into a standard electrochemical cell, at room temperature, under dynamic conditions, being in open contact with the air. In our previous studies the same devices and methodology were used [22-28].

The cyclic voltammetry was carried out on platinum electrode with an active area of $2 \mathrm{~cm}^{2}$, ensuring a distance between anode and cathode of $3.0 \mathrm{~cm}$, coupling the $\mathrm{Ag} / \mathrm{AgCl}$ electrode, as reference. The cyclic voltammograms were recorded with a potential scan rate of $100 \mathrm{mV} \cdot \mathrm{s}^{-1}$ starting from $-2.0 \mathrm{~V}$ and ending at $2.0 \mathrm{~V}$. The mode of operation and laboratory equipment were described in other previous studies of ours [22-24,26].

The electrolysis was performed using a standard electrochemical cell (volume $100 \mathrm{~cm}^{3}$ ) with two electrodes manufactured from platinum plates with an active area of $2.0 \mathrm{~cm}^{2}$. As in our previous studies $[25,28]$, the measurements were performed in a dynamic regime, at room temperature, being applied a constant current density of $50 \mathrm{~mA} \cdot \mathrm{cm}^{-2}$ for a well determined time. Before measurements, the platinum electrodes were immersed in concentrated $\mathrm{HNO}_{3}$ solution for $4 \mathrm{~h}$ and thoroughly washing with distilled water. Any traces of fatty substances were removed by ultrasonically cleaning in ethanol solution, for $15 \mathrm{~min}$. The electrical contact was ensured by a platinum wire embedded in a Teflon body.

\subsection{UV-Vis Spectrophotometry}

CFTX solutions, before and after cyclic voltammetry and during electrolysis, were analyzed by UV-Vis spectroscopy using, as in our early studies $[25,28]$, a Varian Cary UVVis spectrophotometer (Varian Inc., Mulgrave, VIC, Australia) with CaryWin UV software, version 3.0(303). The UV-Vis spectra were registered in the wavelength ranging from 800 to $200 \mathrm{~nm}$ at different times, as follows: NaF/CFTX - at each 5 min for $60 \mathrm{~min} ; \mathrm{NaCl} / \mathrm{CFTX}$ at each $2 \mathrm{~min}$ for $60 \mathrm{~min}$; NaBr/CFTX —at each $2 \mathrm{~min}$ for $30 \mathrm{~min}$; NaI/CFTX—at each min for $3 \mathrm{~min}$. In our early studies the equipment and way of working were presented.

\section{Results and Discussion}

\subsection{Electrochemical Behavior of CFTX in the Presence of Different Ions}

\subsubsection{Study by Cyclic Voltammetry (CV)}

The CFTX electrochemical behavior depends on the specific interactions of the antibiotic molecules with halides as well as with the electrogenerated species during anodic potential scanning. The electrocatalytic effect of platinum electrode (Pt) on the CFTX electrochemical degradation was also identified.

Figure 1 displays the cyclic voltammograms obtained on Pt electrode in the support electrolyte solution containing $0.1 \mathrm{~mol} \cdot \mathrm{L}^{-1} \mathrm{NaX}\left(\mathrm{X}=\mathrm{F}^{-}, \mathrm{Cl}^{-}, \mathrm{Br}^{-}, \mathrm{I}^{-}\right)$, in the absence and in the presence of $0.025 \mathrm{~g} \cdot \mathrm{L}^{-1} \mathrm{CFTX}$.

For the supporting electrolyte solution containing $\mathrm{F}^{-}$(Figure 1a), on the anodic scan a small peak at $-0.8 \mathrm{~V}$ can be observed which corresponds to platinum hydroxide/oxyhydroxide formation and their adsorption on electrode surface [33-35], reactions (1), (2) and (3).

$$
\begin{gathered}
\mathrm{Pt}+\mathrm{H}_{2} \mathrm{O} \leftrightarrow \mathrm{Pt}(\mathrm{OH})+\mathrm{H}^{+}+\mathrm{e}^{-} \\
\mathrm{Pt}+2 \mathrm{H}_{2} \mathrm{O} \leftrightarrow \mathrm{Pt}(\mathrm{OH})_{2}+2 \mathrm{H}^{+}+2 \mathrm{e}^{-} \\
\mathrm{Pt}+3 \mathrm{H}_{2} \mathrm{O} \leftrightarrow \mathrm{PtO}(\mathrm{OH})_{2}+4 \mathrm{H}^{+}+4 \mathrm{e}^{-}
\end{gathered}
$$




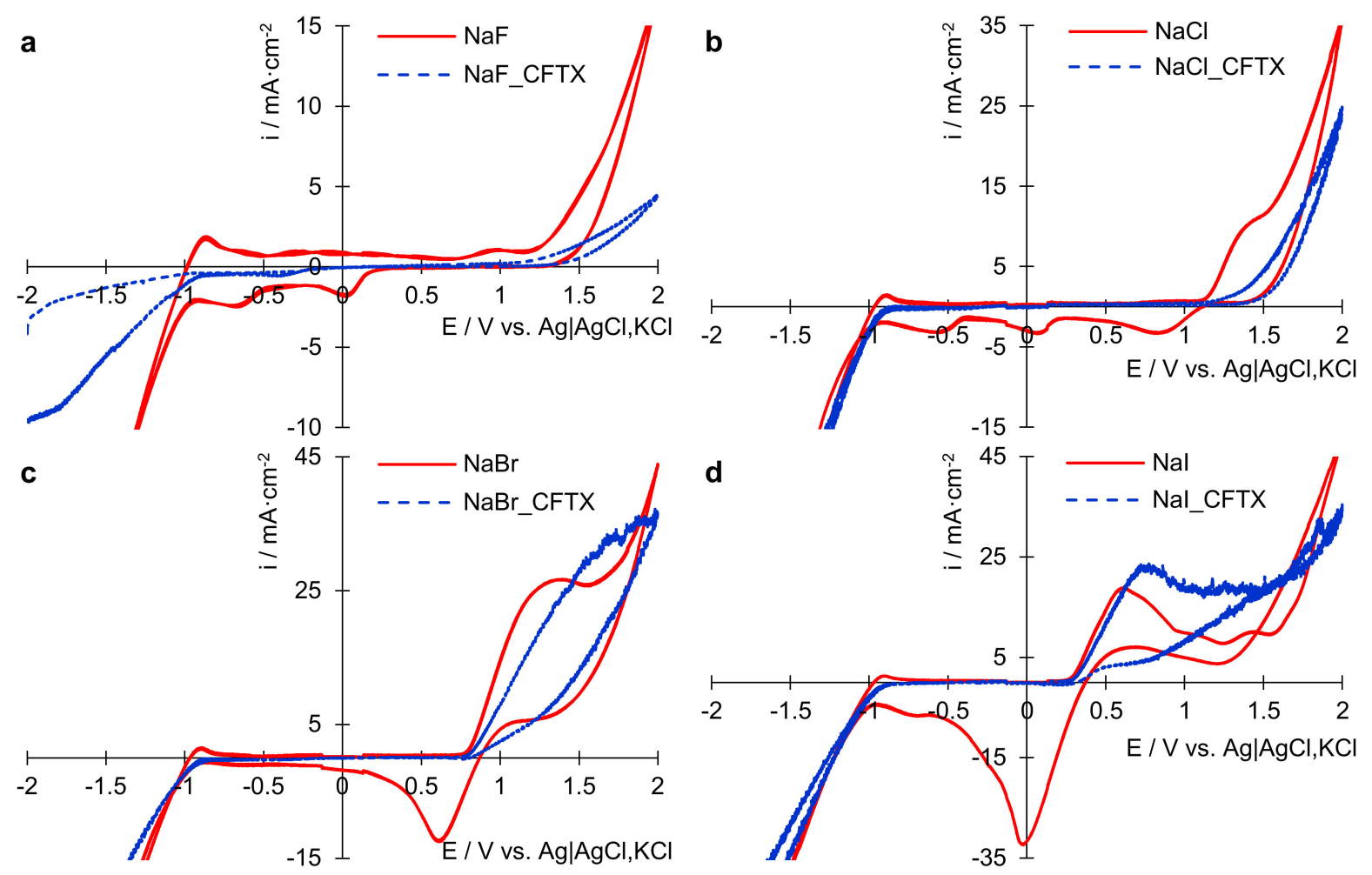

Figure 1. Cyclic voltammograms recorded on platinum electrode in blank support electrolytes and support electrolytes containing $0.025 \mathrm{~g} \cdot \mathrm{L}^{-1} \mathrm{CFTX}$ with a potential scan rate of $100 \mathrm{mV} \cdot \mathrm{s}^{-1}$ : (a) $0.1 \mathrm{~mol} \cdot \mathrm{L}^{-1} \mathrm{NaF}$ solution without and with CFTX; (b) $0.1 \mathrm{~mol} \cdot \mathrm{L}^{-1} \mathrm{NaCl}$ solution without and with CFTX; (c) $0.1 \mathrm{~mol} \cdot \mathrm{L}^{-1} \mathrm{NaBr}$ solution without and with CFTX; (d) $0.1 \mathrm{~mol} \cdot \mathrm{L}^{-1} \mathrm{NaI}$ solution without and with CFTX.

At higher potential values, between 1.0 and $1.8 \mathrm{~V}$, the platinum oxides are formed and adsorbed on the platinum electrode surface (reactions (4)-(9)) followed by oxygen evolution (10) [35-39].

$$
\begin{aligned}
\mathrm{Pt}(\mathrm{OH}) & \leftrightarrow \mathrm{PtO}+\mathrm{H}^{+}+\mathrm{e}^{-} \\
\mathrm{Pt}+\mathrm{H}_{2} \mathrm{O} & \leftrightarrow \mathrm{PtO}+2 \mathrm{H}^{+}+2 \mathrm{e}^{-} \\
\mathrm{Pt}+2 \mathrm{H}_{2} \mathrm{O} & \leftrightarrow \mathrm{PtO}_{2}+4 \mathrm{H}^{+}+4 \mathrm{e}^{-} \\
\mathrm{Pt}+\mathrm{O}_{2}+\mathrm{H}^{+}+\mathrm{e} & \leftrightarrow \mathrm{PtO}(\mathrm{OH}) \leftrightarrow \mathrm{PtO}+\mathrm{H}^{+}+\mathrm{e}^{-} \\
\mathrm{Pt}+\mathrm{H}_{2} \mathrm{O} & \leftrightarrow \mathrm{Pt}(\mathrm{OH})+\mathrm{H}^{+}+\mathrm{e}^{-} \\
\mathrm{Pt}(\mathrm{OH}) & \leftrightarrow \mathrm{PtO}+\mathrm{H}^{+}+\mathrm{e}^{-} \\
2 \mathrm{PtO} & \leftrightarrow 2 \mathrm{Pt}+\mathrm{O}_{2}
\end{aligned}
$$

Fluoride ions are electrochemically inert, and consequently the cathodic peaks correspond to platinum oxide reduction, oxygen reduction and hydrogen evolution (reactions (11), (12) and (13)) [35-39].

$$
\begin{array}{cc}
\mathrm{O}_{2}+\mathrm{e}^{-} \rightarrow \mathrm{O}^{2-} & -1.0 \mathrm{~V} \\
\mathrm{O}_{2}+\mathrm{H}^{+}+\mathrm{e}^{-} \rightarrow \mathrm{HO}_{2} . & -0.05 \mathrm{~V} \\
2 \mathrm{H}_{3} \mathrm{O}^{+}+2 \mathrm{e}^{-} \rightarrow \mathrm{H}_{2}+\mathrm{H}_{2} \mathrm{O} & 0.0 \mathrm{~V}
\end{array}
$$

In the presence of CFTX, the two anodic peaks were suppressed; the oxygen evolution reaction is reduced while that of hydrogen is accelerated and, consequently, the current density following the same trend. On the other hand, the addition of CFTX in the NaF solution leads to a narrower hysteresis and located in lower current areas compared to that 
obtained in its absence. Also, the anodic path overlaps the cathode one, in the potential range between $-1.0 \mathrm{~V}$ and $1.0 \mathrm{~V}$, suggesting that the oxidation/reduction processes at the electrode/electrolyte interface are much restricted due to CFTX adsorption on the platinum surface.

Figure $1 \mathrm{~b}$ shows cyclic voltammograms of the platinum electrode in $0.1 \mathrm{~mol} \cdot \mathrm{L}^{-1}$ $\mathrm{NaCl}$ solution without and with $0.025 \mathrm{~g} \cdot \mathrm{L}^{-1} \mathrm{CFTX}$. It can be observed that, on the curve corresponding to supporting electrolyte ( $\mathrm{NaCl}$ solution) an anodic large peak is highlighted $(1.3 \mathrm{~V})$ related to the oxidation of chloride ions via chlorine to oxychlorides such as $\mathrm{ClO}^{-}$, $\mathrm{ClO}_{2}{ }^{-}, \mathrm{ClO}_{3}{ }^{-}$and $\mathrm{ClO}_{4}{ }^{-}[23,26]$. Also, the anodic current density reached a maximum of $35 \mathrm{~mA} \cdot \mathrm{cm}^{-2}$, higher than that revealed in the case of $\mathrm{NaF}\left(15 \mathrm{~mA} \cdot \mathrm{cm}^{-2}\right)$. Through the cathodic scan (Figure 1b) three reduction peaks are recorded, at potentials of $0.8 \mathrm{~V}$, $0.1 \mathrm{~V}$ and $-0.5 \mathrm{~V}$, being attributed to oxychlorides reduction. In the case of the CFTX/Fsystem (Figure 1a), similar effects on the histogram are described with those previously discussed for the CFTX/ $\mathrm{Cl}^{-}$(Figure 1b), in the sense that no oxidation/reduction peaks are detectable, and at potentials lower than $1.0 \mathrm{~V}$ the anodic and cathodic scans overlap.

The major difference consists of the current density increase until $25 \mathrm{~mA} \cdot \mathrm{cm}^{-2}$, in the presence of $\mathrm{Cl}^{-}$(Figure $1 \mathrm{~b}$ ) compared to that recorded in the presence of $\mathrm{F}^{-}$of $5 \mathrm{~mA} \cdot \mathrm{cm}^{-2}$ (Figure 1a). Thus, it can be concluded that CFTX was adsorbed on the electrode surface, inhibiting the oxidation processes, but a certain small proportion of CFTX can decompose and/or can react with $\mathrm{Cl}^{-}$ions.

The cyclic voltammogram obtained on platinum electrode in sodium bromide supporting electrolyte (Figure 1c) displays an oxidation large peak (like a wave), starting at $0.7 \mathrm{~V}$ and continuing up to $1.5 \mathrm{~V}$, being assigned to simultaneous oxidation processes of bromide ions and to the oxygen evolution according to reaction 10 [40-42]. Also, this oxidation peak is more extensive compared to those recorded in the presence of $\mathrm{F}^{-}$and $\mathrm{Cl}^{-}$ions (Figure 1a,b), suggesting that more intense chemical processes take place in $\mathrm{Br}^{-}$presence (Figure 1c). In the presence of CFTX in sodium bromide solution (Figure 1c), the hysteresis shape is changed, the maximum anodic current density slightly decreases and the anodic and cathodic peaks are imperceptible, indicating that the electrogenerated oxybromides rapidly react with drug molecules forming other compounds.

A different platinum electrochemical behavior was observed in NaI solution (Figure 1d), when iodine $\left(\mathrm{I}_{2}\right)$ is generated by oxidation of iodide ions, being accelerated by molecular oxygen formed according to reaction 10 [42]. The cathodic process is intensified through the reduction of active species, being revealed by a peak that extends up to a high current density of $30 \mathrm{~mA} \cdot \mathrm{cm}^{-2}$. CFTX addition in NaI solution (Figure 1d) leads to a formation of a broad peak on anodic scan, which has a corresponding one slightly nuanced on the cathodic scan, at the same potential, suggesting that multiple processes take place implying $\mathrm{CFTX} / \mathrm{I}^{-} / \mathrm{I}_{3}{ }^{-}$system, substantially changing the reaction environment composition.

Consequently, $\mathrm{Cl}^{-}, \mathrm{Br}^{-}$and $\mathrm{I}^{-}$ions are electrochemically oxidized leading to the occurrence of various halogenated/oxyhalogenated species which can act as powerful oxidants on organic compounds.

\subsubsection{Spectrophotometric Study}

UV-Vis spectra of CFTX, before and after CV performed on platinum electrode in solutions of sodium halides were recorded (Figure 2). As shown in Figure 2, the CFTX spectral characteristics in the presence of $\mathrm{F}^{-}, \mathrm{Cl}^{-}, \mathrm{Br}^{-}$ions (Figure $2 \mathrm{a}-\mathrm{c}$ ) are similar to that obtained in distillated water (inserted spectrum in Figure 2a). In the water, the CFTX absorption maxima were recorded at same wavelength $\left(\lambda_{\max 1}=270 \mathrm{~nm}, \lambda_{\max 2}=240 \mathrm{~nm}\right)$ as the ones obtained in the presence of $\mathrm{F}^{-}, \mathrm{Cl}^{-}, \mathrm{Br}^{-}$ions.

Analyzing the UV-Vis spectra of CFTX shown in Figure 2 it was found that (i) in the presence of $\mathrm{F}^{-}$, the spectra recorded before and after $\mathrm{CV}$ are superimposed (Figure 2a), indicating that the antibiotic is stable, acting by adsorption on the platinum electrode surface; (ii) $\mathrm{Cl}^{-}$ions activate CFTX molecules leading to their partial decomposition, after $\mathrm{CV}$, which causes the concentration decrease and the absorbance one, respectively, with- 
out altering the CFTX spectrum shape or the baseline and wavelength corresponding to the absorbance maximum (Figure 2b); (iii) $\mathrm{Br}^{-}$ions affect the CFTX spectrum, after CV, highlighting a single absorption maximum (Figure 2c), confirming that CFTX molecules interact with the electrogenerated species leading to structural modifications of the functional groups and/or of the initial structure; (iv) in the presence of iodide ions the CFTX spectrum before $\mathrm{CV}$ is completely different from those previously discussed, probably due to the instantaneous chemical interactions/interferences between the antibiotic and the iodide species from solution (Figure 2d). Thus, after the CV, the environment composition is completely changed, and CFTX is no longer identifiable (Figure 2d) due to its total degradation.
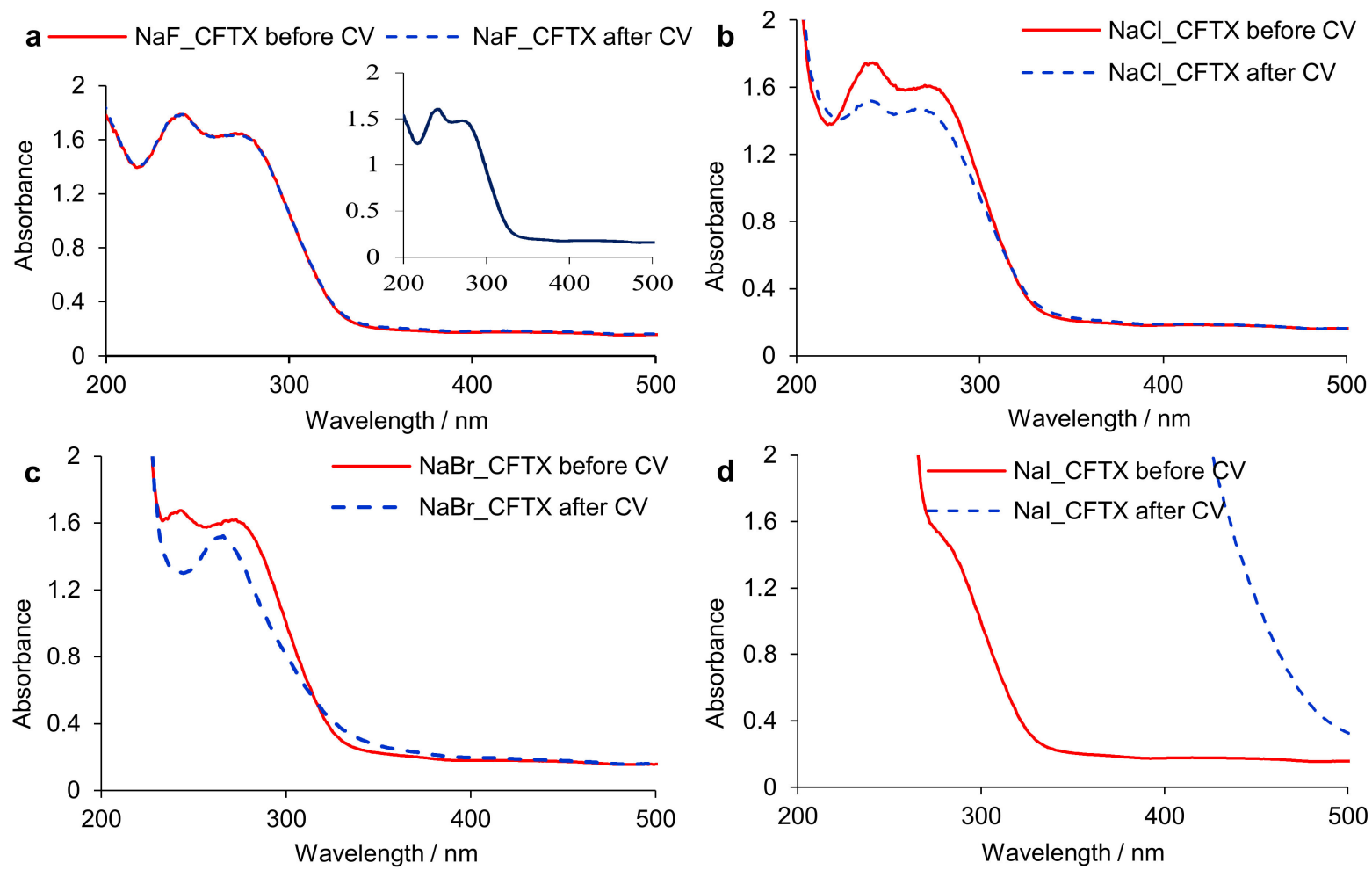

Figure 2. CFTX UV-Vis spectra recorded before and after cyclic voltammetry (CV): (a) CFTX/sodium fluoride solution; (b) CFTX/sodium chloride solution; (c) CFTX/sodium bromide solution; (d) CFTX/sodium iodide solution.

Correlating the data obtained from cyclic voltammetry, when an external stimulus was applied for a short time (40 s), with those provided by UV-Vis spectrophotometry, it was found that (i) CFTX is stable in the presence of the fluoride ion; (ii) CFTX degrades, in the presence of the chloride ion, without highlighting the occurrence of a reaction product; (iii) CFTX degrades in the presence of the bromide ion revealing the appearance of a new reaction product, in a short time; (iv) CFTX interacts rapidly with iodide species, causing the drastic change of reaction environment composition and CFTX chemical structure alteration, before measurements begin.

\subsubsection{Electrolysis Assisted by UV-Vis Spectrophotometry}

Figure 3 displays the UV-Vis spectra of $0.025 \mathrm{~g} \cdot \mathrm{L}^{-1} \mathrm{CFTX}$ aqueous solution in the presence of different $0.1 \mathrm{~mol} \cdot \mathrm{L}^{-1} \mathrm{NaX}$ solutions (where $\mathrm{X}$ was one by one: $\mathrm{F}^{-}, \mathrm{Cl}^{-}, \mathrm{Br}^{-}, \mathrm{I}^{-}$), at different electrolysis times. The CFTX spectrum shows two absorption peaks at $270 \mathrm{~nm}$ and $240 \mathrm{~nm}$ (Figure 3a) according to $\pi \rightarrow \pi^{*}$ and $\mathrm{n} \rightarrow \mathrm{n}^{*}$ electronic transitions $[18,19,30]$. It can be observed that the CFTX has a different behavior in each individual solution. In the presence of fluoride anions, the intensities of the two absorption peaks present a slow 
decreasing trend (Figure 3a) with increasing electrolysis time, suggesting that the CFTX is heterogeneously electrochemically degraded.
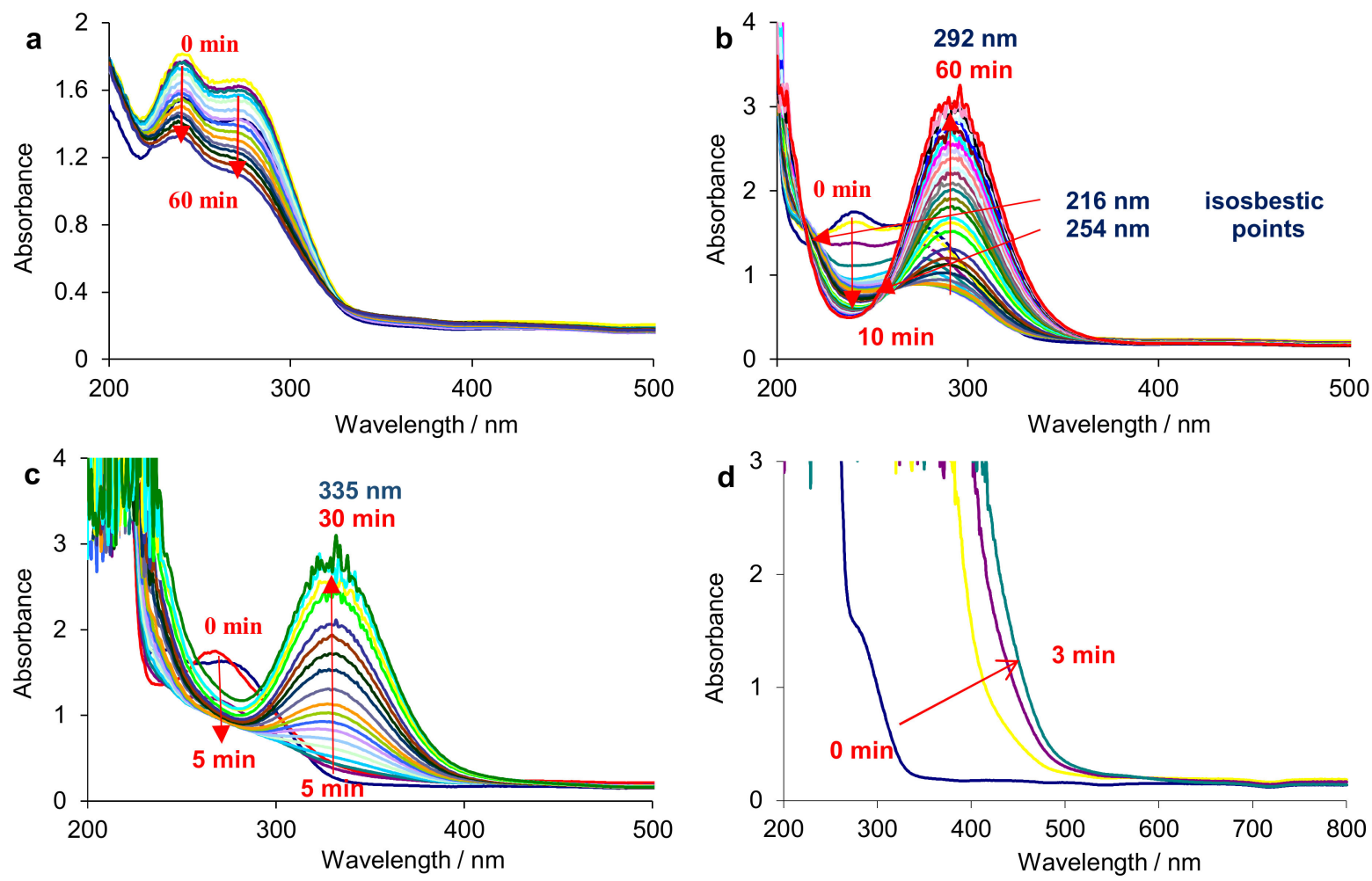

Figure 3. UV-Vis spectra of CFTX recorded on platinum electrode, in solutions of sodium halides during constant current electrolysis: (a) CFTX/NaF solution; (b) CFTX/NaCl solution; (c) CFTX/NaBr solution; (d) CFTX/NaI solution.

During electrolysis, strong oxidized species are electrogenerated on platinum surface, such as $\mathrm{XO}_{\mathrm{n}}^{-}(\mathrm{X}=\mathrm{Cl}, \mathrm{Br}, \mathrm{I} ; \mathrm{n}=1,2,3,4)$, due to the electrooxidation of halide ions from supporting electrolyte. Consequently, there is a mediated electrooxidation by hydroxyl radicals electrogenerated from water decomposition and by $\mathrm{XO}_{\mathrm{n}}^{-}$electrogenerated from supporting electrolyte [30,32]. These oxy and oxyhalogenated species can react both at the electrode surface and in the bulk of solution (indirect electrochemical degradation).

As shown in Figure 3b,c, both absorption peaks decrease proportionally with the time. After $10 \mathrm{~min}$ and $5 \mathrm{~min}$, respectively, these peaks are no longer detectable. As the intensity of absorbance maximum decreases, a new peak appears at $292 \mathrm{~nm}$, in the $\mathrm{Cl}^{-}$presence (Figure $3 \mathrm{~b}$ ), and at $335 \mathrm{~nm}$, in the $\mathrm{Br}^{-}$presence (Figure 3c) leading to the occurrence of a new chemical compound due to the oxygenated species of chlorine and bromine. The adsorption maximum of this compound increases over time, meaning that the peak is a consequence of multiple interactions and interferences between several compounds, which can occur from successive reactions between different species from the supporting electrolyte.

On the other hand, two isosbestic points are registered ( $216 \mathrm{~nm}$ and $254 \mathrm{~nm}$ ), being characteristic to an invariant absorbance transition from CFTX degradation to $\mathrm{XO}_{\mathrm{n}}^{-}$electrogeneration. These results demonstrate the competitive interactions of CFTX molecules with oxy/oxyhalogenated species. Comparison between Figure $3 b, c$ reveals a higher degradation degree of CFTX, in the presence of bromide ions than in the presence of chloride ions, suggesting that the oxybromides have a higher binding affinity.

From Figure 3d, it is observed that a strong interaction of CFTX molecules with iodide ions take place. The spectrophotogram registered at initial time $(t=0 \mathrm{~min})$ shows a small intensity peak at $270 \mathrm{~nm}$, that could result from an overlapping of the CFTX spectrum and the iodine spectrum. 
The data obtained from constant current density electrolysis sustain those provided by cyclic voltammetry, in the sense that in the presence of $\mathrm{F}^{-}$, CFTX is gradually degraded for $60 \mathrm{~min}$; in the presence of $\mathrm{Cl}^{-}$and $\mathrm{Br}^{-}, \mathrm{CFTX}$ rapidly degradation, is followed by electrotransformation into other compounds; the effects of iodinated species are major, and the reaction medium composition is likely to be complex.

\subsection{Kinetic Study of CFTX Degradation Reaction}

The quantification of electrochemical degradation processes was highlighted approaching different kinetic models.

The experimental data obtained by spectrophotometric analysis were fitted according to kinetics of zero and first order reactions using the specific equations resulting from the linear diagrams obtained as $\mathrm{A}=\mathrm{f}(\mathrm{t})$ and $\ln \left(\mathrm{A}_{0} / \mathrm{A}\right)=\mathrm{f}(\mathrm{t})$, respectively, where $\mathrm{A}_{0}$ and $\mathrm{A}$ represent the absorbance values at initial time and at the well-determined moment " $\mathrm{t}$ ". Practically, the slopes of the straight lines represent the rate constants $(\mathrm{k})$ of reactions. To better explain the application of kinetics, it is necessary to show the equations that express the variation of the CFTX concentration, noted further as [CFTX], over time, for each of the kinetics. The Equations (14) and (15) reveal the variation of CFTX concentration in time, for the kinetics of zero and first-order reactions.

$$
\begin{gathered}
-\frac{\mathrm{d}[\mathrm{CFTX}]}{\mathrm{dt}}=\mathrm{k} \\
-\frac{\mathrm{d}[\mathrm{CFTX}]}{\mathrm{dt}}=\mathrm{k}[\text { CFTX }]
\end{gathered}
$$

Since the absorbance is directly proportional to the CFTX concentration, Equations (14) and (15) can be written as follows (Equations (16) and (17)):

$$
\begin{aligned}
& -\frac{\mathrm{dA}}{\mathrm{dt}}=\mathrm{k} \\
& -\frac{\mathrm{dA}}{\mathrm{dt}}=\mathrm{kA}
\end{aligned}
$$

Consequently, by integrating the last two expressions, the rate equations corresponding to the kinetics of zero and first order reactions are obtained (Equations (18) and (19)).

$$
\begin{aligned}
& \mathrm{A}=\mathrm{A}_{0}-\mathrm{kt} \\
& \ln \frac{\mathrm{A}_{0}}{\mathrm{~A}}=\mathrm{kt}
\end{aligned}
$$

where $t$ represents the time (minutes) and $\mathrm{k}$ is the reaction rate constant.

Thus, for zero-order reactions the absorbance varies in the same way, according to the Equation (18). Contrary, for the first-order reactions the absorbance presents an exponential drop (Equation (20)).

$$
\mathrm{A}=\mathrm{A}_{0} \mathrm{e}^{-\mathrm{kt}}
$$

Consequently, (i) for the reactions respecting a zero-order kinetics, by plotting $A=f(t)$, a straight line will be obtained whose slope $(\mathrm{dA} / \mathrm{dt})$ is equal to the rate constant $(\mathrm{k})$, and the intersection with the ordinate represents the initial absorbance $\left(\mathrm{A}_{0}\right)$; (ii) for first order kinetics, the graph $\ln \left(\mathrm{A}_{0} / \mathrm{A}\right)=\mathrm{f}(\mathrm{t})$ represents a straight line with a slope equal to $\mathrm{k}$, and the graph $A=f(t)$ shows the exponential tendency of the absorbance (Equation (20)).

In order to approach the kinetic model related to the CFTX decomposition reaction, the experimental data obtained in the presence of $\mathrm{F}^{-}, \mathrm{Cl}^{-}$and $\mathrm{Br}^{-}$ions were collected. As observed from Figure $4 \mathrm{a}$, in the presence of $\mathrm{I}^{-}$ions, the spontaneous interferences and/or interactions between CFTX and $\mathrm{I}^{-}$species with spectrophotometric response at $290 \mathrm{~nm}$ occur (Figure 4a), being clearly visible for the $0.1 \mathrm{~mol} \mathrm{~L}^{-1} \mathrm{NaI}$ solution. For dilute $\mathrm{NaI}$ solutions $\left(0.01 \mathrm{~mol} \mathrm{~L}^{-1}\right.$ and $\left.0.001 \mathrm{~mol} \mathrm{~L}^{-1}\right)$, a much-attenuated response is highlighted, 
that alters the wavelength of absorbance maximum (detail from Figure $4 b$ ), but which does not exclude the appearance of interferences that affect the spectral characteristics of CFTX. As can be seen from Figure $4 \mathrm{a}$, in the presence of dilute NaI solutions the interferences are slightly weaker, registering a maximum absorption like a shoulder, which follows a descending trend, affecting the baseline to the same extent as in the case of $0.1 \mathrm{~mol} \mathrm{~L}^{-1}$ $\mathrm{NaI}$ solution. Thus, the extension of the experiments for dilute NaI solutions would lead to similar results to those were presented in the previous paragraphs, for the $0.1 \mathrm{~mol} \mathrm{~L}^{-1} \mathrm{NaI}$ solution. Thus, in this case the approach of a kinetic model is improper.
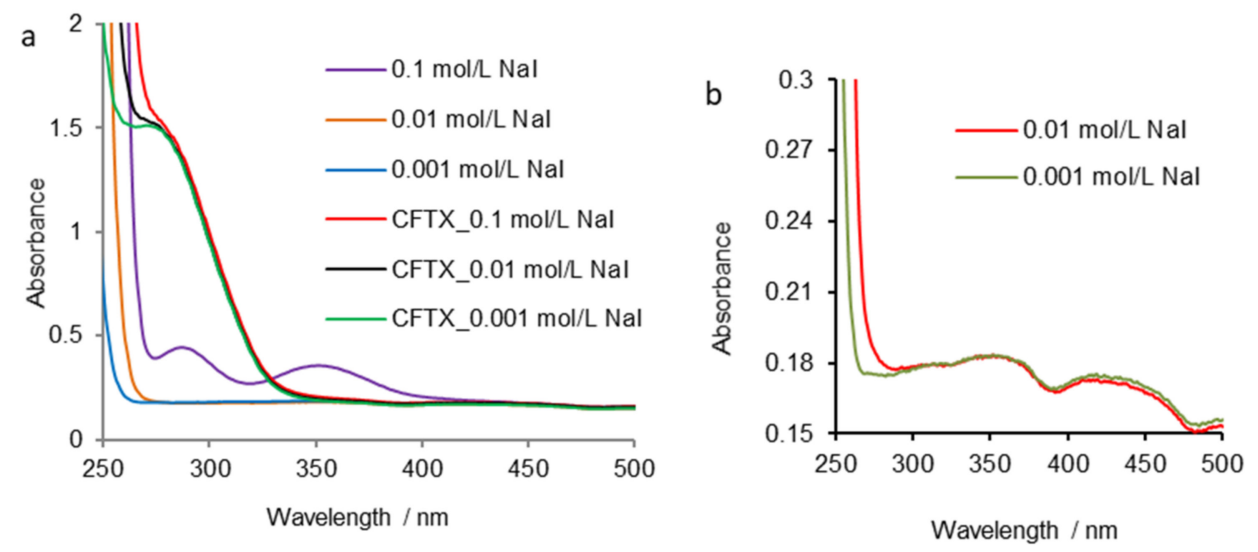

Figure 4. UV-Vis spectra of NaI solution of various concentrations in the absence and presence of CFTX (a) and detailed UV-Vis spectra for $0.01 \mathrm{~mol} \mathrm{~L}^{-1}$ and $0.001 \mathrm{~mol} \mathrm{~L}^{-1}$ respectively, NaI solution (b).

Kinetic data are comparatively presented to those obtained for CFTX degradation in an inert supporting electrolyte, such as sodium sulfate.

The UV-Vis spectra of CFTX in $0.1 \mathrm{~mol} \mathrm{~L}^{-1} \mathrm{Na}_{2} \mathrm{SO}_{4}$ solution recorded during electrolysis and the kinetic model that best fits the experimental data are shown in Figure 5.
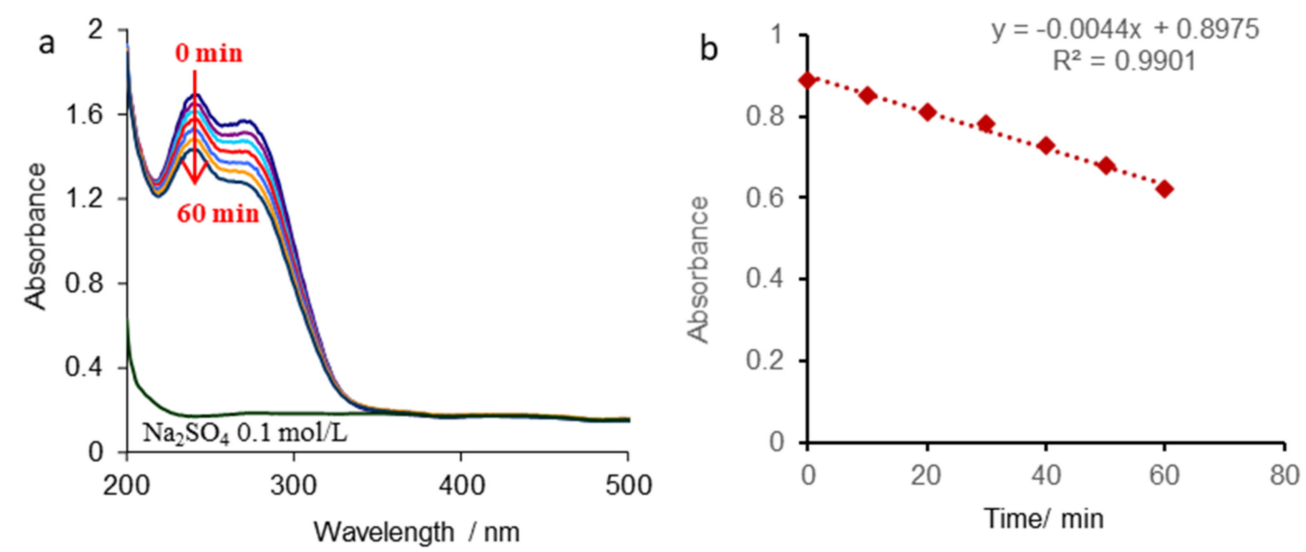

Figure 5. UV-Vis spectra of CFTX in $0.1 \mathrm{~mol} \mathrm{~L}^{-1} \mathrm{Na}_{2} \mathrm{SO}_{4}$ solution obtained during electrolysis at constant current density of $50 \mathrm{~mA} \mathrm{~cm}^{-2}$ (a) and kinetic model of CFTX degradation reaction in the presence of $\mathrm{SO}_{4}{ }^{2-}$ ions (b).

As can be seen from Figure 5a, the CFTX UV-Vis spectra present approximately similar characteristics to those obtained in the presence $\mathrm{F}^{-}$ions. The absorbance maximum decreases over time without altering the wavelength, and another decomposition compound isn't detected.

As shown in Figure $5 b$, the absorbance shows a linear decrease with a mean square deviation very close to unity $\left(R^{2}=0.99\right)$, according to the inserted equation, thus respecting a zero-order reaction kinetics. By derivation, the line slope is obtained, and consequently a 
rate constant value of $0.0044 \mathrm{uA} \mathrm{min}^{-1}$. The final degradation takes place after $204 \mathrm{~min}$, when $\mathrm{y}=0$ and $\mathrm{A}=0$, respectively.

Similarly, the best fitting of the experimental data, for the CFTX degradation reaction, was obtained according to the kinetics of the zero-order reactions, in the presence of $\mathrm{F}^{-}$ and $\mathrm{Cl}^{-}$ions (Figure 6a,b). Smaller values for rate constant compared to that obtained in $0.1 \mathrm{~mol} \mathrm{~L}^{-1} \mathrm{Na}_{2} \mathrm{SO}_{4}$ solution were computed as follows, $0.0096 \mathrm{uA} \mathrm{min}{ }^{-1}$, for CFTX/Fsystem and $0.1677 \mathrm{uA} \mathrm{min}{ }^{-1}$, for CFTX $/ \mathrm{Cl}^{-}$system leading to a final degradation time of $84 \mathrm{~min}$ and $5.5 \mathrm{~min}$, respectively.
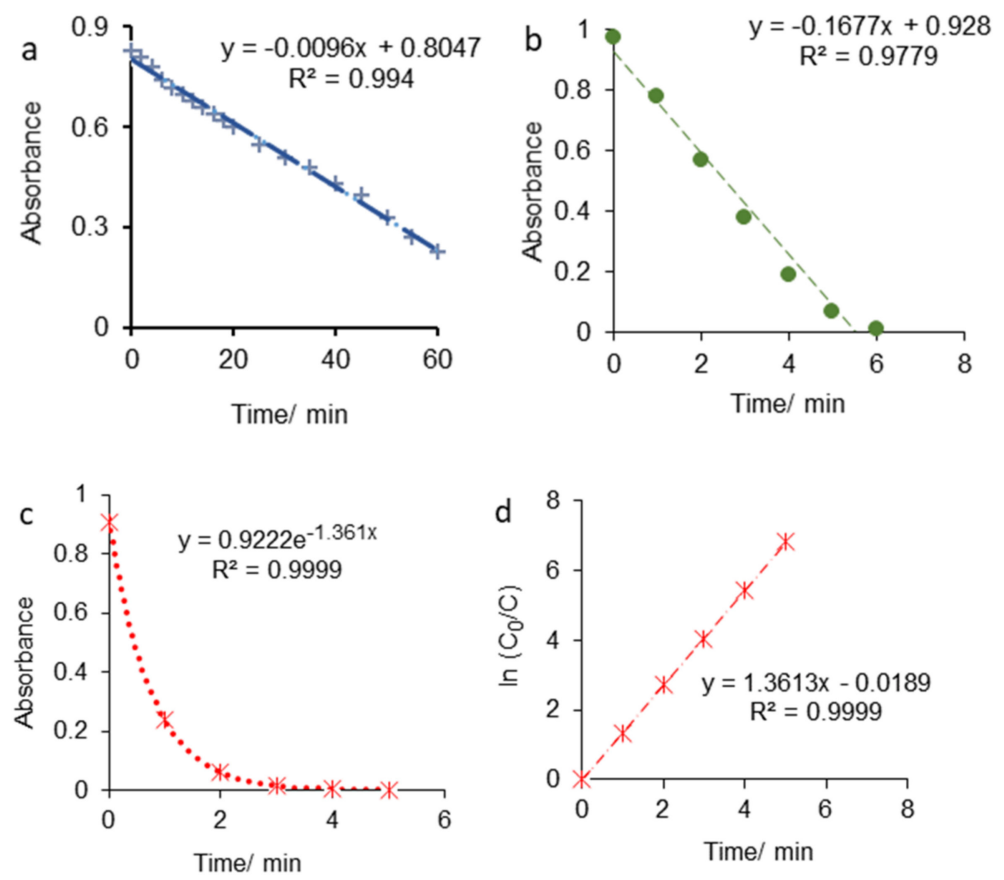

Figure 6. The kinetic models applied for CFTX degradation reaction: (a) in presence of $\mathrm{F}^{-}$; (b) in presence of $\mathrm{Cl}^{-} ;(\mathbf{c}, \mathbf{d})$ in presence of $\mathrm{Br}^{-}$.

In the presence of $\mathrm{Br}^{-}$ions the CFTX degradation obeys the first-order reaction kinetics (Figure $6 c, d$ ). The rate constant high value of $1.361 \mathrm{uA} \mathrm{min}^{-1}$ was calculated from both equations inserted in Figure $6 c, d$, but, according to these kinetics, no final degradation time can be determined, due to the exponential drop in absorbance showing that CFTX reminiscence does not degrade. As shown in Figure $6 \mathrm{a}$, after 3 min a minimum absorbance threshold is reached followed by a plateau approximately identified with zero value, and CFTX degradation percentage is close to $100 \%$. The data are centralized in Table 2.

Table 2. Kinetic data for CFTX degradation reaction in different supporting electrolytes.

\begin{tabular}{cccc}
\hline CFTX/Supporting Electrolyte & Applied Kinetic Model & $\mathbf{k} / \mathbf{m i n}^{-1}$ & Final Degradation Time/min \\
\hline CFTX $/ \mathrm{SO}_{4}{ }^{2-}$ & Zero-order reaction kinetics & 0.0044 & 204 \\
$\mathrm{CFTX} / \mathrm{F}^{-}$ & Zero-order reaction kinetics & 0.0096 & 84 \\
$\mathrm{CFTX} / \mathrm{Cl}^{-}$ & Zero-order reaction kinetics & 0.1677 & 5.5 \\
$\mathrm{CFTX} / \mathrm{Br}^{-}$ & First-order reaction kinetics & 1.361 & 3 min (degradation percentage close to 100\%) \\
\hline
\end{tabular}

\subsection{CFTX Electrochemical Degradation Mechanism}

A mechanism of CFTX pure degradation is proposed, without speculating on the reaction products that are formed due to the interactions between CFTX and chlorine, bromine and iodine species.

In the ground state there are no $n-\pi$ or $\pi-\pi$ electronic conjugations between the thiazole side chain $\left(\mathrm{R}_{1}-\mathrm{CONH}-\right)$ or triazine side chain $\left(\mathrm{R}_{2}\right)$ and the cephalosporin core 
structure (R) (Figure 7). During the processes of electrochemical transformation of CFTX, intermediate structures with $n$ and/or $\pi$ electrons delocalized over the $R_{1}, R_{2}$ and the cephalosporin core structure can be formed. In the thiazole side chain (R1-CONH-), the thiazole ring has a high stability, so that the process of electrochemical degradation can be initiated in the acetylamino group (amide) and/or in the methoxyimino group.

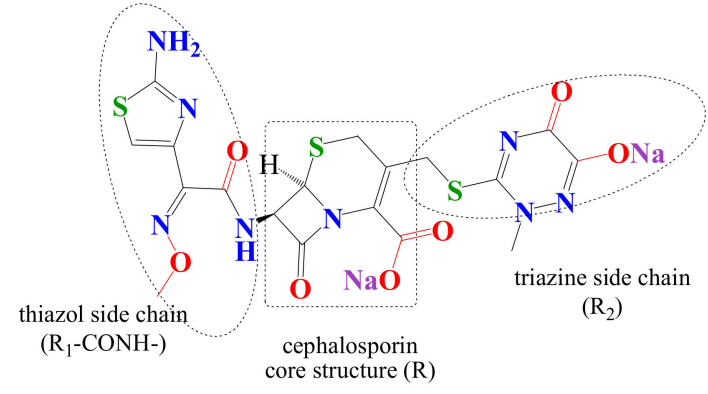

Figure 7. Molecular structure of ceftriaxone (CFTX).

Scheme 1 shows a possible mechanism of electrochemical transformation of the substituent $\mathrm{R}_{1}-\mathrm{CONH}$ - The sulfur atom of sulfide groups (thioether) is electrochemically oxidized to the corresponding sulfoxide $[7,19]$.
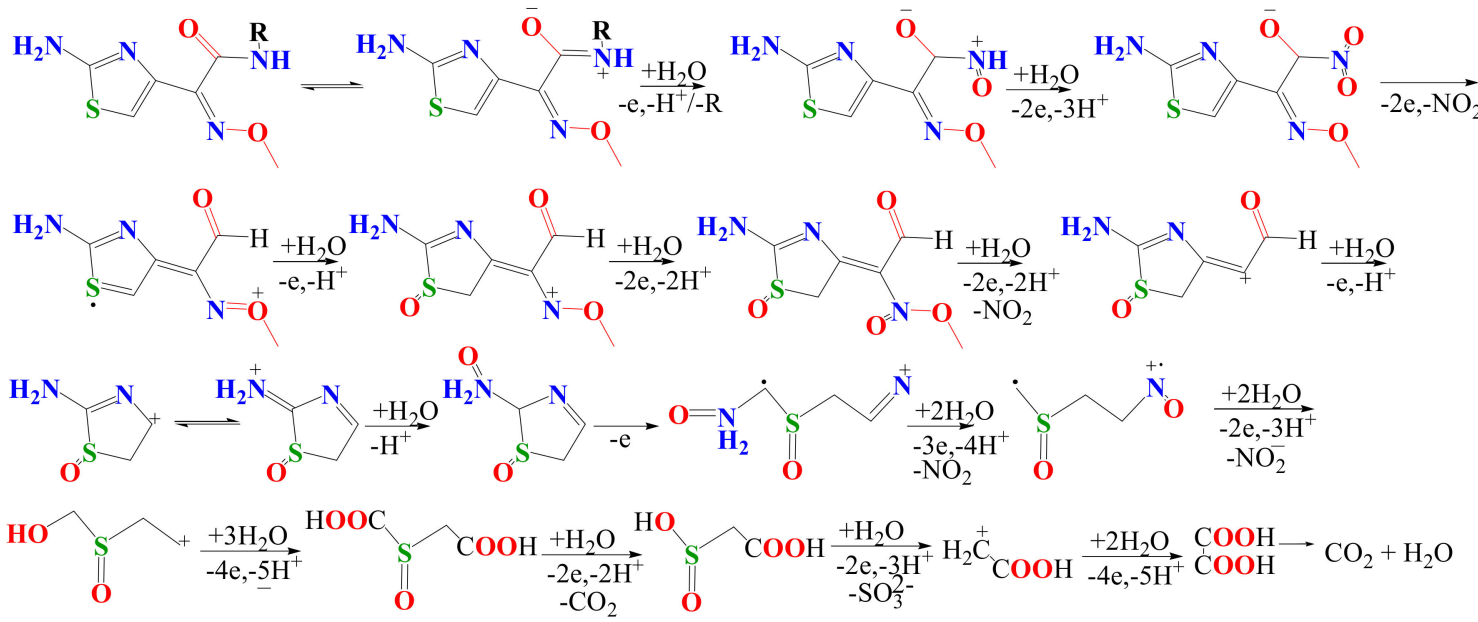

Scheme 1. The pathway for electrochemical oxidation of thiazole side chain ( $\left.\mathrm{R}_{1}-\mathrm{CONH}-\right)$.

The lateral chain $\left(R_{1}\right.$ and $\left.R_{2}\right)$ of cephalosporin core structure may influence both the potential and the current density value of electrochemical degradation [43,44]. Nitrogen atoms as amino, imine, imide, aza or azo groups, also are oxidized to higher oxidation state like nitroso or nitro derivatives (Schemes 1-3).

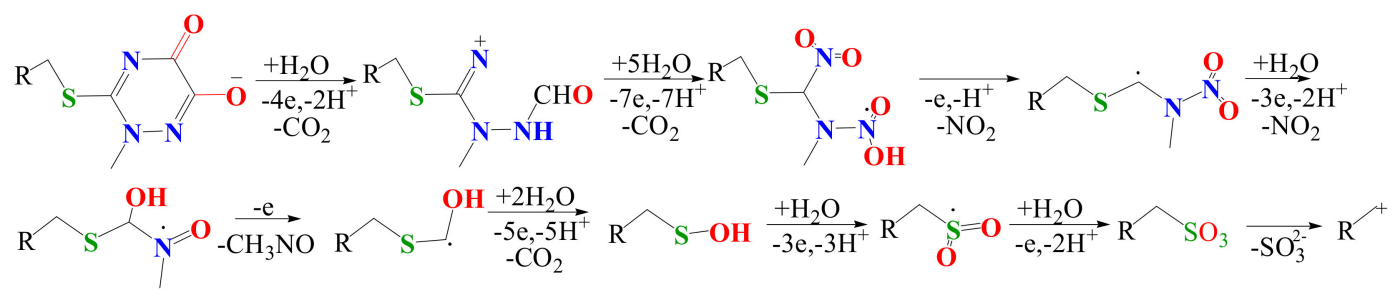

Scheme 2. The pathway for electrochemical oxidation of triazine side chain $\left(R_{2}\right)$.

The mechanism of electrochemical mineralization of a biologically active compound involves successive, concurrent or parallel electrochemical and chemical steps that depend on the electrode potential or current densities [43-46]. 


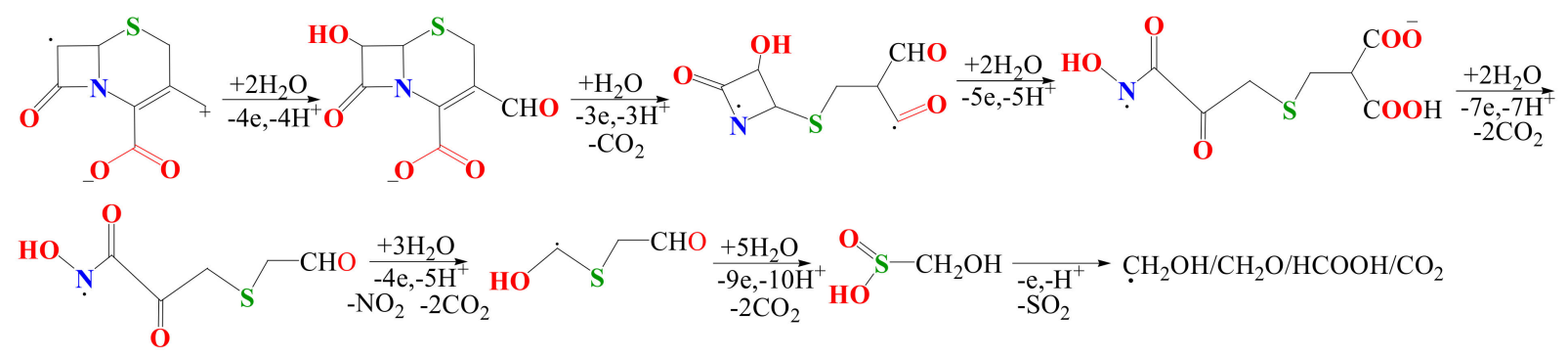

Scheme 3. The pathway for electrochemical oxidation of cephalosporin core structure (R).

Partial electrochemical mineralization and even more, total electrochemical mineralization of such a compound leads to total/partial of its antimicrobial activity decrease, while intermediate or final degradation compounds can affect human health [19,32].

\section{Conclusions}

The present study investigated the ceftriaxone electrochemical degradation in aqueous simulated solutions under laboratory conditions.

The CFTX electro(degradation/transformation) is dependent on both the structural transformation of antibiotic molecules and electrolyte composition. The CFTX degradation reaction exhibits a parallelism between heterogeneous direct electrochemical oxidation and homogenous indirect chemical oxidation by oxy/oxyhalogenated species $\mathrm{XO}_{\mathrm{n}}^{-}(\mathrm{X}=\mathrm{Cl} ; \mathrm{Br}$; $\mathrm{I} ; \mathrm{n}=1,2,3,4)$.

Before electrochemical measurements, instantaneous interactions/interferences between CFTX and iodine species take place, which did not allow an appropriate kinetic model to be approached. In the case of other halide ions, the interactions between CFTX molecules and active species from supporting electrolytes attest to the antibiotic instability varying as follows: CFTX $/ \mathrm{Br}^{-}>\mathrm{CFTX} / \mathrm{Cl}^{-}>\mathrm{CFTX} / \mathrm{F}^{-}>\mathrm{CFTX} / \mathrm{SO}_{4}{ }^{2-}$. The kinetic data confirm that the rate constants follow the same trend, the highest value of $1.361 \mathrm{uA} \mathrm{min}^{-1}$ being obtained in the $\mathrm{Br}^{-}$presence and the smallest value of $0.0044 \mathrm{uA} \mathrm{min}{ }^{-1}$, in $\mathrm{Na}_{2} \mathrm{SO}_{4}$ solution.

The study shows that concomitant administration of ceftriaxone with other natural preparations/pharmaceuticals containing chlorine, bromine or iodine should be considered with caution. However, in the human body such high potentials are not reached, meaning that the intra-molecular interactions between species can be less intense than those discussed above.

The electrochemical degradation method in the presence of sodium fluoride is an environmentally friendly and clean technique, but requires relatively high energy consumption. It could be successfully applied to the purification of medical wastewater containing low concentrations of antibiotics.

Author Contributions: Conceptualization, A.S. (Adriana Samide) and B.T.; methodology, B.T.; investigation, B.T. and S.I.; resources, C.T.; A.S. (Andreea Simionescu); A.P.; writing-original draft preparation, B.T.; writing-review and editing, A.S. (Adriana Samide), A.P.; funding acquisition, B.T., S.I., C.T., A.S. (Andreea Simionescu). All authors have read and agreed to the published version of the manuscript.

Funding: This research received no external funding.

Institutional Review Board Statement: Not applicable.

Informed Consent Statement: Not applicable.

Acknowledgments: The funding of this work was supported by the research grants awarded by the University of Craiova, Romania, in the competition "The Awards of Research Results-ISI Articles".

Conflicts of Interest: The authors declare no conflict of interest. 


\section{References}

1. Ribeiro, A.R.; Sures, B.; Schmidt, T.C. Cephalosporin antibiotics in the aquatic environment: A critical review of occurrence, fate, ecotoxicity and removal technologies. Environ. Pollut. 2018, 241, 1153-1166. [CrossRef] [PubMed]

2. Yu, X.; Tang, X.; Zuo, J.; Zhang, M.; Chen, L.; Li, Z. Distribution and persistence of cephalosporins in cephalosporin producing wastewater using SPE and UPLC-MS/MS method. Sci. Total Environ. 2016, 569-570, 23-30. [CrossRef] [PubMed]

3. El-Shaboury, S.R.; Saleh, G.A.; Mohamed, F.A.; Rageh, A.H. Analysis of cephalosporin antibiotics. J. Pharm. Biomed. Anal. 2007, 45, 1-19. [CrossRef] [PubMed]

4. Sengun, F.I.; Ulas, K. Analytical investigations on cephalosporins-I Spectrophotometric determination of ceftriaxone. Talanta 1986, 33, 363-365. [CrossRef]

5. Ivaska, A.; Nordstrom, F. Determination of some cephalosporins by differential pulse polarography and linear scan voltammetry. Anal. Chim. Acta 1983, 146, 87-95. [CrossRef]

6. Foog, A.G.; Fayad, N.M. Differential pulse polarography determination of cephalosporins and their degradation products. Anal. Chim. Acta 1979, 108, 205-211. [CrossRef]

7. Feier, B.; Gui, A.; Cristea, C.; Săndulescu, R. Electrochemical determination of cephalosporins using a bare boron-doped diamond electrode. Anal. Chim. Acta 2017, 976, 25-34. [CrossRef]

8. Jiang, M.; Wang, L.; Ji, R. Biotic and abiotic degradation of four cephalosporin antibiotics in a lake surface water and sediment. Chemosphere 2010, 80, 1399-1405. [CrossRef]

9. Zhao, W.; Zhang, Y.; Li, Q. Indirect spectrophotometric determination of sodium ceftriaxone with n-propyl alcohol-ammonium sulfate-water system by extraction flotation of copper(II). Clin. Chim. Acta 2008, 391, 80-84. [CrossRef]

10. Reynoso, E.; Spesia, M.B.; García, N.A.; Biasutti, M.A.; Criado, S. Riboflavin-sensitized photooxidation of Ceftriaxone and Cefotaxime. Kinetic study and effect on Staphylococcus aureus. J. Photoch. Photobio. B 2015, 142, 35-42. [CrossRef]

11. Yang, B.; Zuo, J.; Li, P.; Wang, K.; Yu, X.; Zhang, M. Effective ultrasound electrochemical degradation of biological toxicity and refractory cephalosporin pharmaceutical wastewater. Chem. Eng. J. 2016, 287, 30-37. [CrossRef]

12. Sacco, O.; Vaiano, V.; Rizzo, L.; Sannino, D. Intensification of ceftriaxone degradation under UV and solar light irradiation in presence of phosphors based structured catalyst. Chem. Eng. Process. 2019, 137, 12-21. [CrossRef]

13. Kordestani, B.; Yengejeh, R.J.; Takdastan, A.; Neisi, A.K. A new study on photocatalytic degradation of meropenem and ceftriaxone antibiotics based on sulfate radicals: Influential factors, biodegradability, mineralization approach. Microchem. J. 2019, 146, 286-292. [CrossRef]

14. Kaur, B.; Kuntus, L.; Tikker, P.; Kattel, E.; Trapido, M.; Dulova, N. Photo-induced oxidation of ceftriaxone by persulfate in the presence of iron oxides. Sci. Total Environ. 2019, 676, 165-175. [CrossRef] [PubMed]

15. Badi, M.Y.; Azari, A.; Pasalari, H.; Esrafili, A.; Farzadkia, M. Modification of activated carbon with magnetic $\mathrm{Fe}_{3} \mathrm{O}_{4}$ nanoparticle composite for removal of ceftriaxone from aquatic solutions. J. Mol. Liq. 2018, 261, 146-154. [CrossRef]

16. Qiao, J.; Lv, M.; Qu, Z.; Zhang, M.; Cui, X.; Wang, D.; Piao, C.; Liu, Z.; Wang, J.; Song, Y. Preparation of a novel Z-scheme $\mathrm{KTaO} 3 / \mathrm{FeVO} 4 / \mathrm{Bi} 2 \mathrm{O} 3$ nanocomposite for efficient sonocatalytic degradation of ceftriaxone sodium. Sci. Total Environ. 2019, 689, 178-192. [CrossRef]

17. Zhao, Y.; Wang, Y.; Liang, X.; Shi, H.; Wang, C.; Fan, J.; Hu, X.; Liu, E. Enhanced photocatalytic activity of Ag-CsPbBr3/CN composite for broad spectrum photocatalytic degradation of cephalosporin antibiotics 7-ACA. Appl. Catal. B-Environ. 2019, 247, 57-69. [CrossRef]

18. Zhao, Y.; Wang, Y.; Shi, H.; Liu, E.; Fan, J.; Hu, X. Enhanced photocatalytic activity of ZnSe QDs/g-C ${ }_{3} \mathrm{~N}_{4}$ composite for Ceftriaxone sodium degradation under visible light. Mat. Lett. 2018, 231, 150-153. [CrossRef]

19. Zhao, Y.; Liang, X.; Shi, H.; Wang, Y.; Ren, Y.; Liu, E.; Zhang, X.; Fan, J.; Hu, X. Photocatalytic activity enhanced by synergistic effects of nano-silver and ZnSe quantum dots co-loaded with bulk g-C3N4 for Ceftriaxone sodium degradation in aquatic environment. Chem. Eng. J. 2018, 353, 56-68. [CrossRef]

20. Shi, X.; Karachi, A.; Hosseini, M.; Yazd, M.S.; Kamyab, H.; Ebrahimi, M.; Parsaee, Z. Ultrasound wave assisted removal of Ceftriaxone sodium in aqueous media with novel nano composite $\mathrm{g}-\mathrm{C}_{3} \mathrm{~N}_{4} / \mathrm{MWCNT} / \mathrm{Bi}_{2} \mathrm{WO}_{6}$ based on CCD-RSM model. Ultrason. Sonochem. 2019, 104460. [CrossRef]

21. Zhao, Y.; Liang, X.; Wang, Y.; Shi, H.; Liu, E.; Fan, J.; Hu, X. Degradation and removal of Ceftriaxone sodium in aquatic environment with $\mathrm{Bi}_{2} \mathrm{WO}_{6} / \mathrm{g}-\mathrm{C}_{3} \mathrm{~N}_{4}$ photocatalyst. J. Colloid Interf. Sci. 2018, 523, 7-17. [CrossRef] [PubMed]

22. Tutunaru, B.; Samide, A.; Neamțu, C.; Prunaru, I. Electrochemical and thermal stability of Brown HT food additive. Chem. Ind. Chem. Eng. Q. 2019, 25, 89-96. [CrossRef]

23. Tutunaru, B.; Samide, A.; Neamtu, C.; Tigae, C. Spectroelectrochemical studies of interactions between vitamin A and nanocolloidal silver. Int. J. Electrochem. Sci. 2018, 13, 5850-5859. [CrossRef]

24. Samide, A.; Tutunaru, B.; Bratulescu, G.; Ionescu, C. Electrochemical synthesis and characterization of new electrodes based on poly-hematoxylin film. J. Appl. Polym. Sci. 2013, 30, 687-697. [CrossRef]

25. Samide, A.; Tutunaru, B.; Cioateră, N.; Vladu, A.C.; Spînu, C.; Tigae, C. Catalytic activity of thallium on electrochemical degradation of Metronidazole from aqueous solutions. Chem. Eng. Commun. 2016, 203, 1572-1581. [CrossRef]

26. Samide, A.; Tutunaru, B. Interactions between vitamin C and nanocolloidal silver particles studied by cyclic voltammetry and UV-Vis spectrophotometry. Electroanalysis 2017, 29, 2498-2506. [CrossRef] 
27. Tutunaru, B.; Samide, A.; Moanţă, A.; Ionescu, C.; Tigae, C. Electrochemical study of metribuzin pesticide degradation on Bi electrode in aqueous solution. Int. J. Electroch. Sci. 2015, 10, 223-234.

28. Samide, A.; Tutunaru, B.; Tigae, C.; Efrem, R.; Moanţă, A.; Dumitru, M. The removal of dyes from wastewater by electrochemical degradation. Environ. Prot. Eng. 2014, 40, 93-104.

29. Zhao, Y.; Wang, Y.; Liu, E.; Fan, J.; Hu, X. $\mathrm{Bi}_{2} \mathrm{WO}_{6}$ nanoflowers: An efficient visible light photocatalytic activity for ceftriaxone sodium degradation. Appl. Surf. Sci. 2018, 436, 854-864. [CrossRef]

30. Guo, X.; Wan, J.; Yu, X.; Lin, Y. Study on preparation of $\mathrm{SnO}_{2}-\mathrm{TiO}_{2} /$ Nano-graphite composite anode and electro-catalytic degradation of ceftriaxone sodium. Chemosphere 2016, 164, 421-429. [CrossRef]

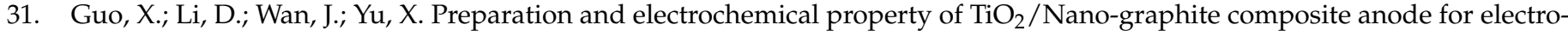
catalytic degradation of ceftriaxone sodium. Electrochim. Acta 2015, 180, 957-964. [CrossRef]

32. Li, D.; Guo, X.; Song, H.; Sun, T.; Wan, J. Preparation of $\mathrm{RuO}_{2}-\mathrm{TiO}_{2} /$ Nano-graphite composite anode for electrochemical degradation of ceftriaxone sodium. J. Hazard. Mater. 2018, 351, 250-259. [CrossRef] [PubMed]

33. Jayasankar, B.; Karan, K. $\mathrm{O}_{2}$ electrochemistry on Pt: A unified multi-step model for oxygen reduction and oxide growth Electrochim. Acta 2018, 273, 367-378. [CrossRef]

34. Rinaldo, S.G.; Lee, W.; Stumper, J.; Eikerling, M. Mechanistic principles of platinum oxide formation and reduction. Electrocatalysis 2014, 5, 262-272. [CrossRef]

35. Birss, V.I.; Chang, M.; Segal, J. Platinum oxide film formation-reduction: An in-situ mass measurement study. J. Electroanal. Chem. 1993, 355, 181-191. [CrossRef]

36. Jaksic, M.M.; Johansen, B.; Tunold, R. Electrochemical behaviour of platinum in alkaline and acidic solutions of heavy and regular water. Int. J. Hydrogen Energ. 1993, 10, 817-837. [CrossRef]

37. Coustan, L.; Shul, G.; Bélanger, D. Electrochemical behavior of platinum, gold and glassy carbon electrodes in water-in-salt electrolyte. Electrochem. Commun. 2017, 77, 89-92. [CrossRef]

38. Pöpke, H.; Mutoro, E.; Luerßen, B.; Janek, J. Oxygen reduction and oxidation at epitaxial model-type Pt $\left(\mathrm{O}_{2}\right) / \mathrm{YSZ}$ electrodes-On the role of PtOx formation on activation, passivation, and charge transfer. Catal. Today 2013, 202, 12-19. [CrossRef]

39. Alsabet, M.; Grden, M.; Jerkiewicz, G. Comprehensive study of the growth of thin oxide layers on Pt electrodes under well-defined temperature, potential, and time conditions. J. Electroanal. Chem. 2006, 589, 120-127. [CrossRef]

40. Huang, X.; Qu, Y.; Cid, C.A.; Finke, C.; Hoffmann, M.R.; Lim, K.; Jiang, S.C. Electrochemical disinfection of toilet wastewater using wastewater electrolysis cell. Water Res. 2016, 92, 164-172. [CrossRef]

41. Mastragostino, M.; Gramellini, C. Kinetic study of the electrochemical processes of the bromine/bromine aqueous system on vitreous carbon electrodes. Electrochim. Acta 1985, 30, 373-380. [CrossRef]

42. Denaro, A.R.; Mitchell, A.; Richardson, M.R. Glow-discharge electrolysis of iodide solutions. Electrochim. Acta 1971, 16, 755-762. [CrossRef]

43. Abo El Maali, N.; Ali, A.M.M.; Khodari, M.; Ghandour, M.A. Cathodic stripping voltammetric determination of the cephalosporin antibiotic Ceftriaxone at the mercury electrode in aqueous and biological media. Bioelectrochem. Bioenerg. 1991, $26,485-492$. [CrossRef]

44. Ribeiro, A.R.; Schmidt, T.C. Determination of acid dissociation constant (pKa) of cephalosporin antibiotics: Computational and experimental approaches. Chemosphere 2017, 169, 524-533. [CrossRef] [PubMed]

45. Tian, Y.; Lu, L.; Chang, Y.; Zhang, D.S.; Li, J.; Feng, Y.C.; Hu, C.Q. Identification of a new isomer from a reversible isomerization of ceftriaxone in aqueous solution. J. Pharm. Biomed. Anal. 2015, 102, 326-330. [CrossRef] [PubMed]

46. Canton, E.; Esteban, M.J.; Rius, F. Factors affecting the stability of ceftriaxone sodium in solution on storage. Int. J. Pharm. 1993, 92, 47-53. [CrossRef] 